\title{
Monitoring of Non-Ferrous Wear Debris in Hydraulic Oil by Detecting the Equivalent Resistance of Inductive Sensors
}

\author{
Lin Zeng ${ }^{1}$, Hongpeng Zhang ${ }^{1, *}$, Qiang Wang ${ }^{2}$ and Xingming Zhang ${ }^{3}$ \\ 1 Marine Engineering College, Dalian Maritime University, Dalian 116026, China; bobzl@dlmu.edu.cn \\ 2 Shanghai Salvage Ministry of Transport, Shanghai 200000, China; wq@cose.cn \\ 3 School of Naval Architecture and Ocean Engineering, Harbin Institute of Technology, Weihai 264209, China; \\ zhxm@hit.edu.cn \\ * Correspondence: zhppeter@dlmu.edu.cn; Tel.: +86-138-4287-2800
}

Received: 29 December 2017; Accepted: 5 March 2018; Published: 8 March 2018

\begin{abstract}
Wear debris in hydraulic oil contains important information on the operation of equipment, which is important for condition monitoring and fault diagnosis in mechanical equipment. A micro inductive sensor based on the inductive coulter principle is presented in this work. It consists of a straight micro-channel and a 3-D solenoid coil wound on the micro-channel. Instead of detecting the inductance change of the inductive sensor, the equivalent resistance change of the inductive sensor is detected for non-ferrous particle (copper particle) monitoring. The simulation results show that the resistance change rate caused by the presence of copper particles is greater than the inductance change rate. Copper particles with sizes ranging from $48 \mu \mathrm{m}$ to $150 \mu \mathrm{m}$ were used in the experiment, and the experimental results are in good agreement with the simulation results. By detecting the inductive change of the micro inductive sensor, the detection limit of the copper particles only reaches $70 \mu \mathrm{m}$. However, the detection limit can be improved to $48 \mu \mathrm{m}$ by detecting the equivalent resistance of the inductive sensor. The equivalent resistance method was demonstrated to have a higher detection accuracy than conventional inductive detection methods for non-ferrous particle detection in hydraulic oil.
\end{abstract}

Keywords: non-ferrous wear debris; micro inductive sensor; hydraulic oil; equivalent resistance method

\section{Introduction}

Hydraulic machinery is widely used in civil and military industries. As the blood of the hydraulic system, hydraulic oil not only has the effect of transmitting energy, but can also reduce friction between components and reduce the system temperature. Wear debris in hydraulic oil contains important information on the operation of the equipment, which is important for condition monitoring and fault diagnosis in mechanical equipment [1]. The detection of hydraulic oil can avoid the possibility of catastrophic component failure during operation [2]. Wear debris is one of the main causes of hydraulic mechanical failure [3,4]. During normal machine operations, the concentration of wear debris in the hydraulic oil remains the same and the particle size is small, typically in the range of 10-20 $\mu \mathrm{m}$. When abnormal wear occurs, the debris concentration gradually increases, and the size of the debris particles increases to as large as 50-100 $\mu \mathrm{m}[5,6]$. Statistics show that more than 80 percent of catastrophic failures are caused by particle contamination in the hydraulic oil [7]. Among these particles, 75 percent are metallic, which cause almost all failures [8,9]. The wear debris in the oil is an important information carrier for machinery wear. Wear debris, especially non-ferrous wear debris, indicates the key component of being worn. Many components in hydraulic systems contain 
non-ferrous metallic material, such as the copper slippers in hydraulic axial piston pumps, white metal linings, tin base white metal linings and the leading white metal linings, which include varieties of non-ferrous metal material. The wear debris will be oxidized if the particles remain in the oil for a long time, which will cause serious damage to the equipment. However, in the early stages of wear, most of the particles still have metallic properties [10]. Therefore, the monitoring of non-ferrous wear debris is essential for initial prediction of hydraulic system failures.

A few oil condition monitoring devices have been developed in recent years [11-13]. Optical methods, such as light blockage counters, are capable of detecting small particles in hydraulic oil [14]. However, the accuracy of the light blockage method is affected by fluid clarity, the particle refractive index and the existence of air bubbles. The acoustic emission detection method, which is based on the amplitude change of reflected acoustic waves, is sensitive to the influence of background acoustic emissions and lubrication oil temperature variations [15]. Rosenkranz et al. developed an electrical resistivity method to test the solid-solid contact ratio in order to detect catastrophic failure in tribological contacts [16] and performed some experimental studies using the wear particle analysis of stainless steel surfaces with periodic cross-like patterns [17]. Capacitive Coulter counting is very simple, but the measured capacitance change often reflects not only the presence of particles but also the changes in lubricant properties, such as the viscosity and total acid number [18]. However, none of these methods can distinguish between ferrous and non-ferrous metallic particles. Du Li developed an inductive counter counting device for wear debris detection [19-21]. Furthermore, the improvement of the coil structure, the external amplification circuit, and the inductance-capacitance (LC) resonance method enhanced the sensitivity [22-26]. By detecting the inductance change, the inductive sensors, which are widely used in the field for oil particle detection, can distinguish between ferromagnetic and non-ferromagnetic metal particles. However, the inductance sensor has a lower sensitivity to non-ferromagnetic particles (such as copper particles). Previous studies have shown that the detection limit of inductive sensors for copper particles is $125 \mu \mathrm{m}$, and by adding a complex LC resonant circuit to the inductive sensor, the detection limit can theoretically reach $55 \mu \mathrm{m}$ [27].

Compared with the traditional inductive sensor, the microfluidic chip-based inductive sensor has a higher detection accuracy. Instead of detecting the inductance change of the inductive sensor, in this paper, the equivalent resistance change of the inductive sensor was detected for non-ferrous particle (copper particles) monitoring based on our 3-D micro solenoid inductance sensor [28], which was published previously. Both the simulation and the experiment results show that the resistance change is more sensitive than the inductance change for non-ferromagnetic metal particle detection.

\section{Sensor Design and Detection Principle}

The micro inductive sensor is shown in Figure 1. It consists of a 3-D solenoid coil, which is the core of the microfluidic inductive sensor, and a micro-channel made using the mold construction method. The main purpose for the mold construction method in building a micro-channel instead of a glass tube is to decrease the distance between the solenoid coil and the particle. In this way, the micro inductive sensor is more sensitive [29]. To build the 3-D solenoid, we first prepared a small steel wire (300 $\mu \mathrm{m}$ in diameter) with its surface polished smooth. Then, a 600 turn 3-D solenoid coil was built by carefully winding the fine copper line $(25 \mu \mathrm{m}$ in diameter, with a thin insulation) around the small steel wire. After the solenoid was formed, a small amount of polydimethylsiloxane (PDMS) was applied to the 3-D solenoid coil and dried in a thermostat to fix the fine copper line. Then, the small steel wire was removed using pincers to form the micro-channel. Finally, the oil sample inlet was made using a punch. The reason for building a 600 turn 3-D solenoid coil instead of a two-layer planar coil was to strengthen the magnetic field and enhance the density of the magnetic flux at the center of the coil.

An alternating current is applied across the 3-D solenoid coil, which induces an alternating magnetic field in the sensor. The impedance of the sensor is calculated by

$$
Z=R+j \omega L
$$


where $j^{2}=-1, Z$ is the impedance of the coil, $R$ and $L$ are the resistance and inductance of the coil, respectively, and $\omega$ is the angular frequency of the alternating current. The impedance $Z$ is determined by the alternating magnetic field. When the oil containing metallic wear debris passes through the sensor, the magnetic field is changed due to the influence of the metallic particles. As a result, the impedance $Z$, as well as the resistance $R$ and the inductance $L$, are also changed.

Due to high permeability, the ferrous metallic particles are magnetized in a high-frequency magnetic field, and the magnetizing field of the particle is in the same direction as the original magnetic field, so the total magnetic flux is enhanced [30]. Compared with the magnetic field of the eddy currents, the magnetizing field of the magnetization is much larger, and the effect of any eddy currents can be ignored, so the coil equivalent inductance will be increased. As a result, a positive inductive change and a positive resistance change will be induced by a ferrous metal particle.

When a non-ferrous metallic particle passes through the center of the coil, there is no magnetization, but an eddy current will be generated inside the particle due to the alternating magnetic field. The magnetic fields from the eddy currents will offset some original magnetic fields, further affecting the magnitude and phase of the current in the solenoid. As a result, the total magnetic flux of the coil will decrease [31], leading to a decrease in the coil inductance and an increase in the coil equivalent resistance. As the AC excitation frequency and eddy currents increase, large decreases in the equivalent inductance and increases in the equivalent resistance are observed. Thus, a negative inductive change and a positive resistance change are induced by a non-ferrous metallic particle. The magnetic field change induced by the non-ferrous metallic particle was simulated using COMSOL software (COMSOL Multiphysics 5.0, COMSOL Inc., Stockholm, Sweden), as shown in Figure 2. The model structure parameters are consistent with the design parameters of the sensor. Non-ferrous metallic particles (copper particles, for example) with different sizes were used to simulate the resistance and inductance changes in the coil. These results are shown in the next section for comparison with the experimental results.

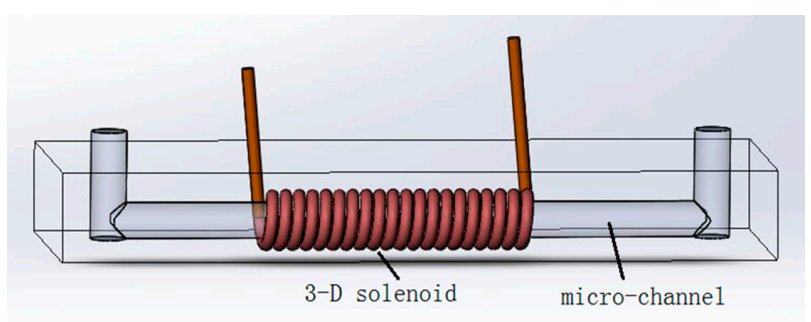

Figure 1. Design of the micro inductive sensor for hydraulic oil detection: the diameters of the solenoid coil and the micro-channel are $25 \mu \mathrm{m}$ and $300 \mu \mathrm{m}$, respectively.

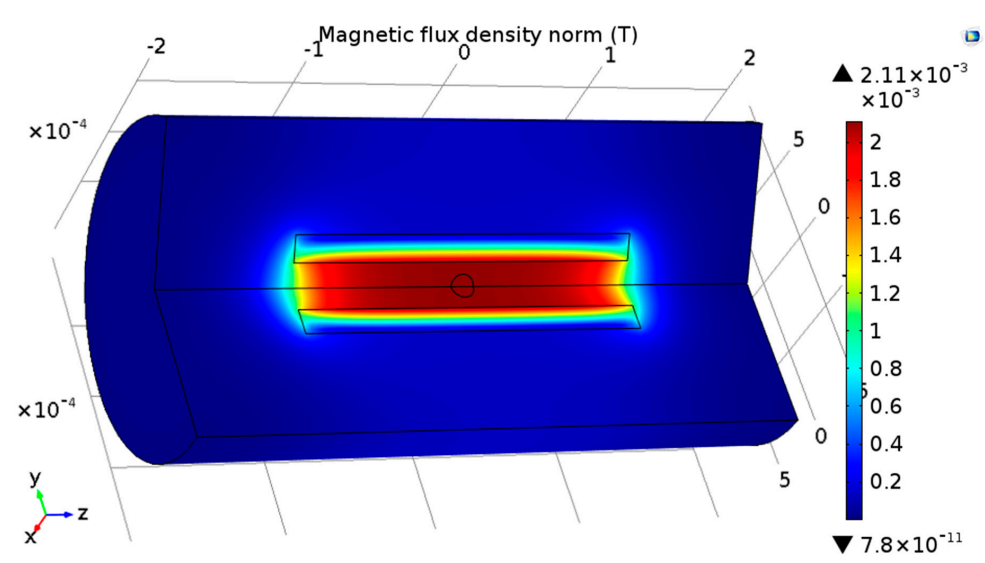

Figure 2. Magnetic field distribution within the sensor as influenced by the non-ferrous metallic particle. 


\section{Experiments and Discussions}

\subsection{Experimental Procedure}

The experimental system is illustrated in Figure 3. It is composed of a syringe pump (Harvard Apparatus B-85259, Harvard Apparatus, Holliston, MA, USA), a microfluidic inductive sensor, an LCR impedance analyzer (Agilent E4980A, Agilent Technologies Inc., Bayan Lepas, Malaysia) and a computer. Copper particles with different sizes are used to test the detection system. A plastic pipe is used to connect the injection pump and the detection chip. The oil sample is injected into the micro-channel and then flows through the center of the solenoid at a controllable velocity. The volume flow of the oil sample is set at $0.04 \mathrm{~mL} / \mathrm{min}$. The LCR meter is connected to the solenoid with an AC excitation applied to it. Therefore, the resistance and inductance of the 3-D solenoid coil can be monitored by the LCR meter. In all experiments, the excitation signal applied to the LCR meter was a $2 \mathrm{MHz}, 2 \mathrm{~V}$ sine wave. The LCR meter was set up to assume that the solenoid coil consists of a pure resistance and inductance in series, and the resistance and inductance of the coil can be detected by the LCR meter simultaneously. When there are no metal particles in the hydraulic oil, the basic resistance and inductance are approximately $61.2 \Omega$ and $54.9 \mu \mathrm{H}$, respectively.

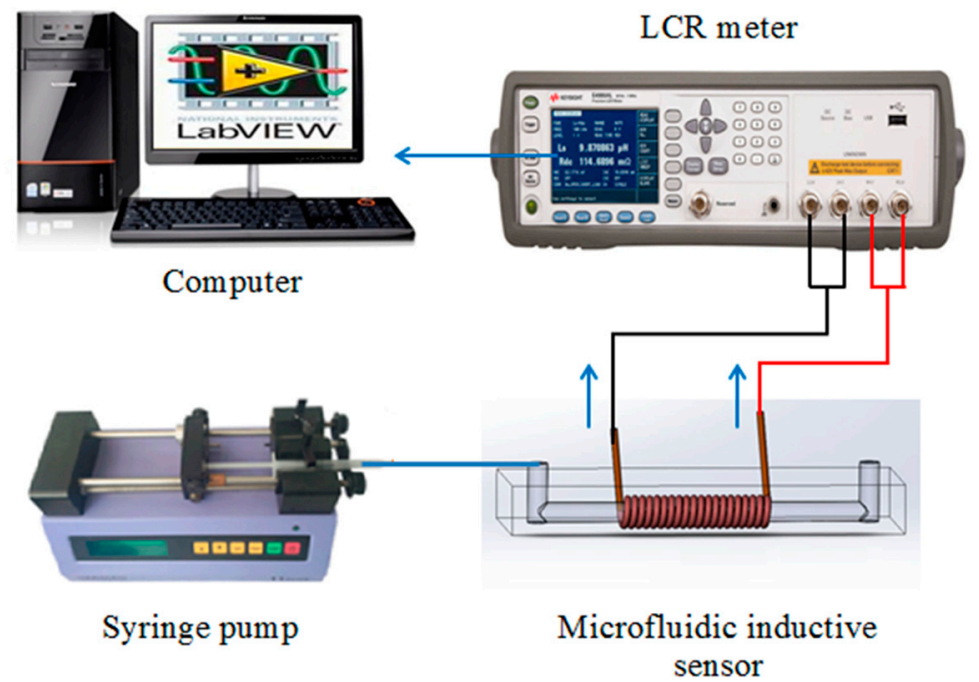

Figure 3. The impedance detection system.

Roughly spherical copper particles (Hefei Shatai Mechanical and electrical technology Co., Ltd., Hefei, China) with different sizes were used in the experiments. A series of steel sieves was used to select copper particles with sizes ranging from $48 \mu \mathrm{m}$ to $53 \mu \mathrm{m}, 58 \mu \mathrm{m}$ to $62 \mu \mathrm{m}, 65 \mu \mathrm{m}$ to $74 \mu \mathrm{m}$, $80 \mu \mathrm{m}$ to $86 \mu \mathrm{m}, 90 \mu \mathrm{m}$ to $96 \mu \mathrm{m}, 96 \mu \mathrm{m}$ to $106 \mu \mathrm{m}$ and $150 \mu \mathrm{m}$ to $160 \mu \mathrm{m}$, within these size ranges, the size of the particles is evenly distributed. In the experiments, the particles with different size were mixed with the corresponding hydraulic oil (The Great Wall L-HM 46, Sinopec Lubricant Co., Ltd., Beijing, China) to create different oil samples with $100 \mathrm{~mL}$ of oil and $4 \mathrm{mg}$ of copper particles. These oil samples were injected into the micro-channel using a syringe pump to start the experiments.

\subsection{Results and Discussions}

The detection results are shown in Figures 4 and 5.

Figure 4 shows the resistance and inductance changes generated by the small copper particles $(48-53 \mu \mathrm{m})$. In the experiments, the sensor has detected 29 particles $(48-53 \mu \mathrm{m})$ in $5 \mathrm{~min}$ using the equivalent resistance method (due to space constraints, we did not put all the detection results in the manuscript), but two of the signals were barely identifiable in the signal diagram, so based on the detection results, the probability of detecting $48-53 \mu \mathrm{m}$ particles is $93.1 \%$. When we detected the 
42-48 $\mu \mathrm{m}$ copper particles, there were only 3 identifiable signals in $5 \mathrm{~min}$, so we considered that the detection limits of the sensor is $48 \mu \mathrm{m}$ copper particles. The average amplitude of the resistance is approximately $0.01 \Omega$; however, the inductance change cannot be detected because the particle size is too small, and the signal is lost within the noise. The resistance and inductance detection results of the copper particles with sizes ranging from $150 \mu \mathrm{m}$ to $160 \mu \mathrm{m}$ are shown in Figure 5. The detection results show that when copper particles flow through the sensor, positive resistance changes and negative inductive changes were observed. Each signal change represents the passage of one copper particle. The average amplitudes of the resistive changes and the inductance changes are approximately $0.76 \Omega$ and $2.36 \times 10^{-8} \mathrm{H}$, respectively, and their signal-to-noise ratios (SNRs) are approximately 152.7 and 47.2 , respectively. The comparison results show that the equivalent resistance change is more sensitive to particle size than the inductance change for non-ferrous metallic particle detection. For the small copper particles, the equivalent resistance method has a lower detection limit than inductance method. Thus, the smaller particles can be detected using the resistance method. For the relatively large copper particles, the equivalent resistance method also has a higher SNR than the inductance method.

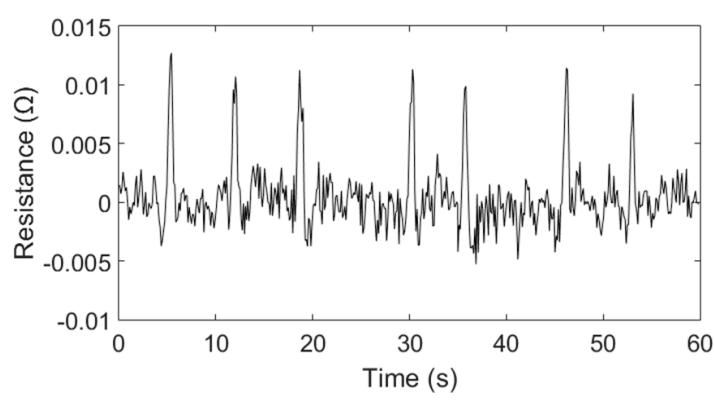

(a)

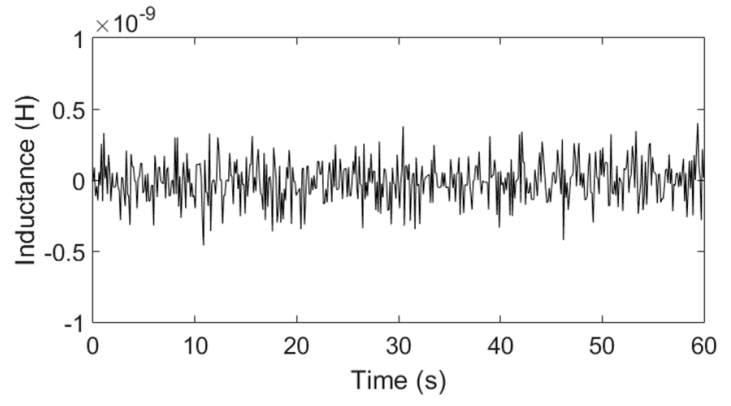

(b)

Figure 4. Detection results of the copper particles with sizes ranging from $48 \mu \mathrm{m}$ to $53 \mu \mathrm{m}$ : (a) Resistance detection results; (b) Inductance detection results.

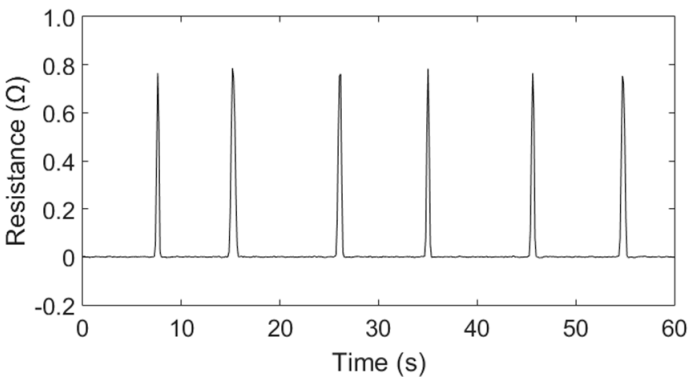

(a)

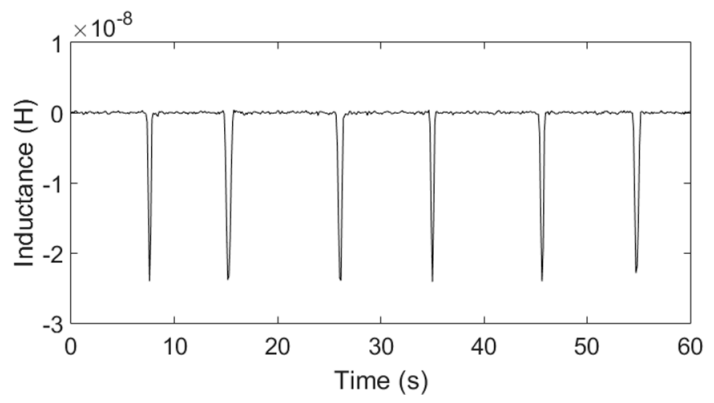

(b)

Figure 5. Detection results of the copper particles with sizes ranging from $150 \mu \mathrm{m}$ to $160 \mu \mathrm{m}$ : (a) Resistance detection results; (b) Inductance detection results.

Next, by calculating the average of 10 detected signal amplitudes for particles of each size, and comparing them with the simulation results, the experimental results were verified. The comparison results are shown in Figure 6.

Figure 6 shows that the experimental results are in good agreement with the simulation results. Both the resistance and inductance changes increase with increasing diameter of the copper particles. In addition, the copper particles with sizes as small as $48 \mu \mathrm{m}$ can be detected using the equivalent resistance method. However, the inductance method can only detect the copper particles with sizes large than $70 \mu \mathrm{m}$. Therefore, the sensitivity and accuracy can be improved by detecting the equivalent 
resistance of the coil. This is of great significance to optimize micro inductive sensors and to enhance the detection precision and accuracy.

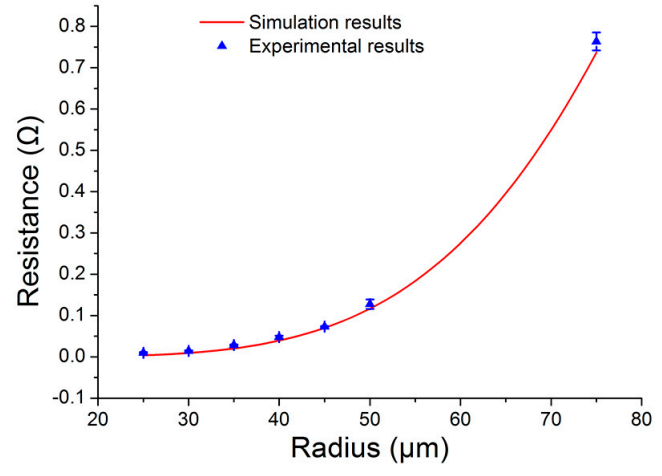

(a)

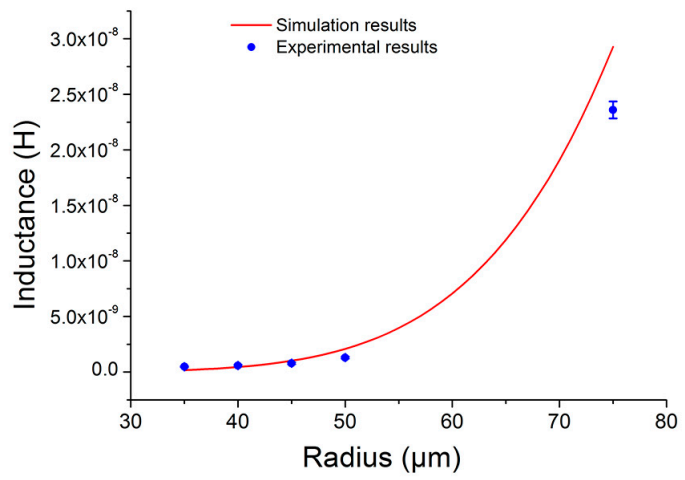

(b)

Figure 6. Comparison of the experimental results and the simulation results: (a) Detection results of the copper particles with diameters ranging from $48 \mu \mathrm{m}$ to $150 \mu \mathrm{m}$; (b) Detection results of the copper particles with diameters ranging from $70 \mu \mathrm{m}$ to $150 \mu \mathrm{m}$.

\section{Conclusions}

In this paper, we demonstrated that an equivalent resistance method improves the sensitivity of a micro inductive sensor for non-ferrous wear debris detection. Instead of monitoring the inductance change in the micro inductive sensor, the equivalent resistance change of the sensor was monitored to detect non-ferrous wear debris in hydraulic oil. The resistance and inductance changes induced by the non-ferrous metallic particles were simulated first using COMSOL software. Then, resistance and inductance detection experiments were performed using copper particles with sizes ranging from $48 \mu \mathrm{m}$ to $150 \mu \mathrm{m}$. The experimental results verify the simulation results. Compared with the $70 \mu \mathrm{m}$ detection limit of the inductance method, we successfully detected $48 \mu \mathrm{m}$ copper particles using the equivalent resistance method. Additionally, both the sensitivity and the SNR of the micro inductive sensor were significantly improved. The new method supports the improvement of micro inductance sensor accuracy, which is of great significance to the rapid detection of non-ferrous wear debris in hydraulic oil.

Acknowledgments: This work was supported by the Natural Science Foundation of China (51679022), the Fundamental Research Funds for the Central Universities (3132017013).

Author Contributions: Lin Zeng and Hongpeng Zhang conceived and designed the experiments; Lin Zeng and Qiang Wang performed the experiments and wrote the first draft of this manuscript; Xingming Zhang aided in harvest and finished writing and editing the manuscript.

Conflicts of Interest: The authors declare no conflicts of interest.

\section{References}

1. Zhang, X.; Zhang, H.; Chen, H.; Zhang, Y.; Sun, Y. Study on the resolution-frequency characteristic of microfluidic oil detection chip. Chin. J. Sci. Instrum. 2014, 35, 427-433.

2. Du, L.; Zhe, J.; Carletta, J.; Veillette, R.; Choy, F. Real-time monitoring of wear debris in lubrication oil using a microfluidic inductive Coulter counting device. Microfluid. Nanofluid. 2010, 9, 1241-1245. [CrossRef]

3. Williams, J.A. Wear and wear particles-Some fundamentals. Tribol. Int. 2005, 38, 863-870. [CrossRef]

4. Hunt, T.M. Handbook of Wear Debris Analysis and Particle Detection in Liquids; Kluwer Academic Publishers Group: Berlin, Germany, 1993; ISBN 978-1-85-166962-2.

5. Tucker, J.E.; Schultz, A.; Lu, C.; Sebok, T.; Holloway, C.; Tankersley, L.L.; Reintjes, J. Lasernet fines optical wear debris monitor. In Proceedings of the International Conference on Condition Monitoring, Swansea, UK, 12-15 April 1999; pp. 445-452. 
6. Edmonds, J.; Resner, M.S.; Shkarlet, K. Detection of precursor wear debris in lubrication systems. In Proceedings of the 2000 IEEE Aerospace Conference Proceedings, Big Sky, MT, USA, 25 March 2000; pp. 73-77.

7. Rao, B. Handbook of Condition Monitoring; Elsevier Advanced Technology: Manchester, UK, 1996; ISBN 978-1-85-617234-9.

8. Iwai, Y.; Honda, T.; Miyajima, T.; Yoshinaga, S.; Higashi, M.; Fuwa, Y. Quantitative estimation of wear amounts by real time measurement of wear debris in lubricating oil. Tribol. Int. 2010, 43, 388-394. [CrossRef]

9. Zhang, H.; Huang, W.; Jin, J.; Guo, L.; Li, D. Debris detection in hydraulic oil using a microfluidic inductive pulse device. In Proceedings of the ASME 2012 Third International Conference on Micro/Nanoscale Heat and Mass Transfer, Atlanta, GA, USA, 3-6 March 2012; pp. 51-57.

10. Toms, A.; Toms, A. Oil analysis and condition monitoring. In Chemistry and Technology of Lubricants; Springer: Dordrecht, The Netherlands, 2010; pp. 459-495.

11. Loutas, T.H.; Roulias, D.; Pauly, E.; Kostopoulos, V. The combined use of vibration, acoustic emission and oil debris on-line monitoring towards a more effective condition monitoring of rotating machinery. Mech. Syst. Signal Process. 2011, 25, 1339-1352. [CrossRef]

12. Appleby, M.; Choy, F.K.; Du, L.; Zhe, J. Oil debris and viscosity monitoring using ultrasonic and capacitance/inductance measurements. Lubr. Sci. 2013, 25, 507-524. [CrossRef]

13. Murali, S.; Jagtiani, A.V.; Xia, X.; Carletta, J.; Zhe, J. A microfluidic Coulter counting device for metal wear detection in lubrication oil. Rev. Sci. Instrum. 2009, 80, 016105. [CrossRef] [PubMed]

14. Nicoli, D.F.; Toumbas, P. Sensors and Methods for High-Sensitivity Optical Particle Counting and Sizing. U.S. Patent US6794671 B2, 21 November 2004.

15. Buttle, D.J.; Scruby, C.B. Characterization of particle impact by quantitative acoustic emission. Wear 1990, 137, 63-90. [CrossRef]

16. Rosenkranz, A.; Martin, B.; Bettscheider, S.; Gachot, C.; Kliem, H.; Mücklich, F. Correlation between solid-solid contact ratios and lubrication regimes measured by a refined electrical resistivity circuit. Wear 2014, 320, 51-61. [CrossRef]

17. Rosenkranz, A.; Heib, T.; Gachot, C.; Mücklich, F. Oil film lifetime and wear particle analysis of laser-patterned stainless steel surfaces. Wear 2015, 334, 1-12. [CrossRef]

18. Murali, S.; Xia, X.; Jagtiani, A.V.; Carletta, J.; Zhe, J. Capacitive coulter counting: Detection of metal wear particles in lubricant using a microfluidic device. Smart Mater. Struct. 2009, 18, 037001. [CrossRef]

19. Du, L.; Zhe, J.; Carletta, J.E.; Veillette, R.J. Inductive Coulter counting: Detection and differentiation of metal wear particles in lubricant. Smart Mater. Struct. 2010, 19, 057001. [CrossRef]

20. Du, L.; Zhe, J. A high throughput inductive pulse sensor for online oil debris monitoring. Tribol. Int. 2011, 44, 175-179. [CrossRef]

21. Du, L.; Zhu, X.; Han, Y.; Zhe, J. High throughput wear debris detection in lubricants using a resonance frequency division multiplexed sensor. Tribol. Lett. 2013, 51, 453-460. [CrossRef]

22. Zeng, L.; Zhang, H.; Zhao, X.; Teng, H.; Yu, Z. Double coil multi-parameter impedance sensor for hydraulic oil pollutants detection. Chin. J. Sci. Instrum. 2017, 38, 1690-1697.

23. Zhang, H.; Zeng, L.; Teng, H.; Zhang, X. A novel on-chip impedance sensor for the detection of particle contamination in hydraulic oil. Micromachines 2017, 8, 249. [CrossRef]

24. Luo, J.; Yu, D.; Liang, M. Enhancement of oil particle sensor capability via resonance-based signal decomposition and fractional calculus. Measurement 2015, 76, 240-254. [CrossRef]

25. Zhu, X.; Chong, Z.; Zhe, J. A high sensitivity wear debris sensor using ferrite cores for online oil condition monitoring. Meas. Sci. Technol. 2017, 28, 075102. [CrossRef]

26. Wang, C.; Liu, X.; Chen, Z. Probe improvement of inductive sensor for online health monitoring of mechanical transmission systems. IEEE Trans. Magn. 2015, 51, 4004404. [CrossRef]

27. Du, L.; Zhu, X.; Han, Y.; Zhan, L.; Zhe, J. Improving sensitivity of an inductive pulse sensor for detection of metallic wear debris in lubricants using parallel LC resonance method. Meas. Sci. Technol. 2013, 24, 075106. [CrossRef]

28. Zhang, H.; Zhang, X.; Guo, L.; Zhang, Y.; Sun, Y. Design of the oil detection microfluidic chip. Chin. J. Sci. Instrum. 2013, 34, 762-767. [CrossRef]

29. Wu, Y.; Zhang, H.; Zeng, L.; Chen, H.; Sun, Y. Determination of metal particles in oil using a microfluidic chip-based inductive sensor. Instrum. Sci. Technol. 2016, 44, 259-269. [CrossRef] 
30. Fan, H.; Zhang, Y.T.; Ren, G.Q.; Li, Z.N. Experimental study of an on-line monitoring sensor for wear particles in oil. Tribology 2010, 30, 338-343.

31. Dziczkowski, L. Effect of eddy current frequency on measuring properties of devices used in non-destructive measurements of non-ferromagnetic metal plates. Arch. Mater. Sci. Eng. 2008, 32, 77-84.

(c) 2018 by the authors. Licensee MDPI, Basel, Switzerland. This article is an open access article distributed under the terms and conditions of the Creative Commons Attribution (CC BY) license (http:/ / creativecommons.org/licenses/by/4.0/). 